\title{
An analysis, systematic review, and meta-analysis of the perioperative mortality after neoadjuvant therapy and pneumonectomy for non-small cell lung cancer
}

\author{
Anthony W. Kim, MD, ${ }^{a}$ Daniel J. Boffa, MD, ${ }^{a}$ Zuoheng Wang, PhD, ${ }^{\mathrm{b}}$ and Frank C. Detterbeck, MD ${ }^{\mathrm{a}}$
}

Objective: Pneumonectomy after neoadjuvant therapy remains controversial.

Methods: A systematic PubMed search was performed for original articles from 1990 through 2010 describing pneumonectomy after neoadjuvant therapy. Specific data on 30-day and 90-day perioperative mortalities were abstracted from these articles. Meta-analysis compared 30-day mortality between right and left pneumonectomy with a fixed-effects model. Comparison between 30-day and 90-day mortalities was also performed.

Results: The search strategy yielded 27 studies. Overall, 30-day and 90-day perioperative mortalities were 7\% and $12 \%$, respectively. Among 15 studies providing side-specific 30-day mortality, cumulative mortalities were $11 \%$ and $5 \%$ for right and left pneumonectomies, respectively. In the meta-analysis that included 10 studies, 30day mortality for right pneumonectomy remained greater than for left pneumonectomy (odds ratio, 1.97; 95\% confidence interval, 1.11-3.49; $P=.02$ ). Among 6 studies providing side-specific 90-day mortality, cumulative mortalities were $20 \%$ and $9 \%$ for right and left pneumonectomies, respectively. In the meta-analysis that included 4 studies, 90-day mortality for right pneumonectomy was greater than for left pneumonectomy (odds ratio, 2.01; 95\% confidence interval, 1.09-3.72; $P=.03$ ). Among 11 studies providing both 30-day and 90 -day mortalities, mortality difference was $5 \%$ (95\% confidence interval, $4 \%-7 \%, P<.0001)$. Pulmonary complications were the most common cause of 30-day and 90-day deaths.

Conclusions: Right pneumonectomy is associated with significantly higher 30-day and 90-day mortalities after neoadjuvant therapy than left pneumonectomy. Also, 90-day mortality for all pneumonectomies appears to be greater than expected, suggesting that the 30-day mortality figure may inadequately assess the perioperative mortality. (J Thorac Cardiovasc Surg 2012;143:55-63)

Earn CME credits at

http://cme.ctsnetjournals.org

Pneumonectomy has been associated with increased morbidity and mortality relative to other pulmonary resections. ${ }^{1}$ In particular, the mortality for pneumonectomy after neoadjuvant therapy has been thought by some to be prohibitively high. ${ }^{2}$ Reports with alarmingly high mortality $(>20 \%)$, however, have been countered by other reports with very low mortality $(<5 \%)$. This leaves unclear the correct approach for a patient with preoperatively identified N2 disease who would need a pneumonectomy. Often, this

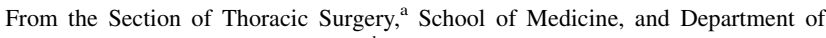
Epidemiology and Public Health, ${ }^{\text {}}$ School of Public Health, Yale University, New Haven, Conn.

Disclosures: Authors have nothing to disclose with regard to commercial support.

Received for publication Aug 19, 2010; revisions received July 30, 2011; accepted for publication Sept 13, 2011; available ahead of print Nov 7, 2011.

Address for reprints: Anthony W. Kim, MD, Assistant Professor, Section of Thoracic Surgery, Yale University, School of Medicine, 330 Cedar St, BB 205, New Haven, CT 06520 (E-mail: anthony.kim@yale.edu).

$0022-5223 / \$ 36.00$

Copyright (c) 2012 by The American Association for Thoracic Surgery doi:10.1016/j.jtcvs.2011.09.002
}

situation involves a large central tumor, which may limit the dose of radiotherapy that can be safely given, also making the alternative of definitive chemoradiation less appealing. Particularly for young patients, in whom the risk of surgical mortality in general is low, it is unclear whether the mortality after neoadjuvant therapy and pneumonectomy is in fact low enough to justify this approach.

The main hypothesis is that the published literature does not support the notion that all pneumonectomies after neoadjuvant therapy are categorically associated with high perioperative mortalities. The primary objective was to demonstrate that right pneumonectomy and not left pneumonectomy in particular is associated with a significantly higher perioperative mortality. The secondary objectives of this review were (1) to determine whether 30-day mortality is different from 90-day mortality and (2) to determine which perioperative complications contribute to perioperative mortality.

\section{MATERIALS AND METHODS}

The Preferred Reporting Items for Systematic reviews and Metaanalysis (PRISMA) guidelines were followed as closely as possible for this systematic review. At the time of the writing of this article, there was no known review protocol specific to the objectives outlined previously. 


\section{Abbreviation and Acronym \\ PRISMA $=$ Preferred Reporting Items for Systematic reviews and Meta-analysis}

\section{Search Strategy}

A comprehensive English-language literature search was performed with the PubMed database to identify published articles (including articles in press and those published exclusively electronically) reporting pulmonary resections after neoadjuvant chemotherapy or chemoradiation therapy between January 1, 1990, and April 30, 2010. A Boolean search strategy was used with the search terms "non-small cell lung cancer" and "pneumonectomy," "induction," and "neoadjuvant." Publications were included if they met the following criteria: (1) they included more than 20 patients who underwent pneumonectomy after neoadjuvant chemotherapy or chemoradiation therapy, (2) they reported the indication for resection was non-small cell lung cancer, and (3) they reported specific perioperative mortality. Publications were excluded for any of the following reasons: (1) central focus of the study on carinal or sleeve pneumonectomy, (2) central focus of the study on extrapleural pneumonectomy, (3) indication for pneumonectomy for disease processes other than non-small cell lung cancer (eg, mesothelioma, small cell lung cancer, or metastatic disease), (4) not more than 20 pneumonectomies, or (5) lack of pneumonectomy-specific data, particularly resection-specific perioperative mortality. Extended pneumonectomies (eg, with pericardial, great vessel, or chest wall resection) were included as long as they did not include carinal or sleeve pneumonectomies. The search further excluded case reports and reviews. Studies from authors or institutions that reported a series that expanded on an earlier series were included; however, the earlier series were not included in these cases. Studies were not excluded on the basis of the type of chemotherapy or chemoradiation therapy regimens that were used.

\section{Data Abstracted}

Specific data that were collected included the period of time in which the patients were either accrued or studied, number of institutions, method of staging, percentage of patients with stage III disease, and the use of neoadjuvant chemotherapy or chemoradiation therapy, including the regimens and doses. The total number of pneumonectomies, the overall 30-day and 90-day mortalities, and the distributions according to the laterality of resection (when available) were also recorded. In the analysis for this review, the 30-day mortality figures actually reflected publications that reported mortality with a specific 30-day period and those reported as any in-hospital mortality. We were not able to separate further in-hospital mortality from 30-day mortality, because that information generally was not provided.

All the articles included in this study were thoroughly reviewed, and the mortalities included reflect either explicit mortality figures that were reported, mortality figures that were calculated from the information provided in the articles not explicitly reporting mortality, or mortality figures abstracted from the discussion of the article if mortality was presented at a meeting but not listed in the original article. If the mortality was neither provided nor calculable on the basis of the existing information, it could not be factored into the analysis. Each article was reviewed several times to ensure that data were neither missed nor erroneously labeled.

Complications that caused or contributed to perioperative mortality were also abstracted and analyzed. The incidence of complications in general was not included, because the definitions and diligence of reporting were highly variable. Complications associated with perioperative death were grouped into 4 broad categories: pulmonary, infectious, cardiac, and other. Pulmonary complications were those complications that included pneumonia, acute respiratory distress syndrome, and atelectasis requiring bronchoscopic intervention. The infectious category comprised bronchopleural fistula and empyema complications. Pneumonia was grouped with pulmonary complications primarily because this is how it was reported in many of the articles. Furthermore, distinguishing actual pneumonia from acute respiratory distress syndrome was not always possible because the distinction was not immediately clear, and often antibiotics are given empirically for patients with acute respiratory distress syndrome. Cardiac complications consisted of cardiac arrhythmias, heart failure, myocardial infarction, and other cardiac issues. The "other" complications included gastrointestinal complications, recurrent laryngeal nerve injury, bleeding or hemothorax, wound issues, and a variety of other nonspecific issues. Venous thromboembolic complications, including pulmonary embolism, were also grouped in this category.

\section{Assessments of Study Quality and Publication Bias}

Because quality scoring in any systematic review or meta-analysis for observational studies is controversial, ${ }^{3-5}$ an internally developed 6-point criteria system was developed to assess quality. The criteria selected were based on clinical factors believed to be associated with improved outcomes and consisted of data that were consistently identifiable as being included or not included in each study. These criteria included the following: size of study, duration of study, era of study, performance in a multicenter paradigm, inclusion of more than half of the patients with stage III disease, and the use of invasive staging. The median duration in years $(<8$ years or $\geq 8$ years) was used to determine whether the study was long or not long. Studies published after and including 1994 or before 1994 were considered later or earlier studies, respectively. The median number of patients included among all the studies $(<68$ or $\geq 68$ ) was used to dichotomize studies as large or not large. The numbers of institutions involved were grouped into 1 versus more than 1 , on the basis of speculation that this difference would be more revealing than a threshold of a given number of multiple institutions (eg, 4 vs $\geq 5$ ). Performance of invasive mediastinal staging routinely in all of the patients versus in some or an unknown number of patients was used to dichotomize the studies.

To be considered highest quality or high quality, at least 4 or 2 , respectively, of the 6 criteria had to be met. Any study with no criteria or 1 criterion was considered to be low quality and was excluded from the analysis. Subgroup analyses of 30-day mortality between highest-quality and highquality studies were performed. If a significant difference was found between highest-quality and high-quality studies, then the Woolf method (inverse variance method) was used for a fixed-effects analysis and the DerSimonian-Laird method was used for a random-effects analysis. The selected studies were further categorized according to the design of the study, and the subset analyses were performed within each design type. The test of heterogeneity in results across studies was carried out with Higgins $I^{2}$, which measures the percentage of total variation across the studies. Publication bias was assessed with Begg funnel plots and Egger tests. If the funnel plot was asymmetric or the $P$ value was less than .05 by Egger test, then a publication bias was assigned.

\section{Statistical Analysis of 30-Day Perioperative Mortality}

The pneumonectomy-specific data were analyzed by a meta-analysis that used a fixed-effects model to compare the 30-day mortality figures between left and right pneumonectomies and to compare 30-day and 90-day mortalities. Statistical analysis was performed with the statistical package $\mathrm{R}$, version 2.10.1. ${ }^{6}$

\section{Study Control}

There was no formal funding source for this study. We as the authors had complete control of the search, data analysis, and writing. No other individuals were involved. 


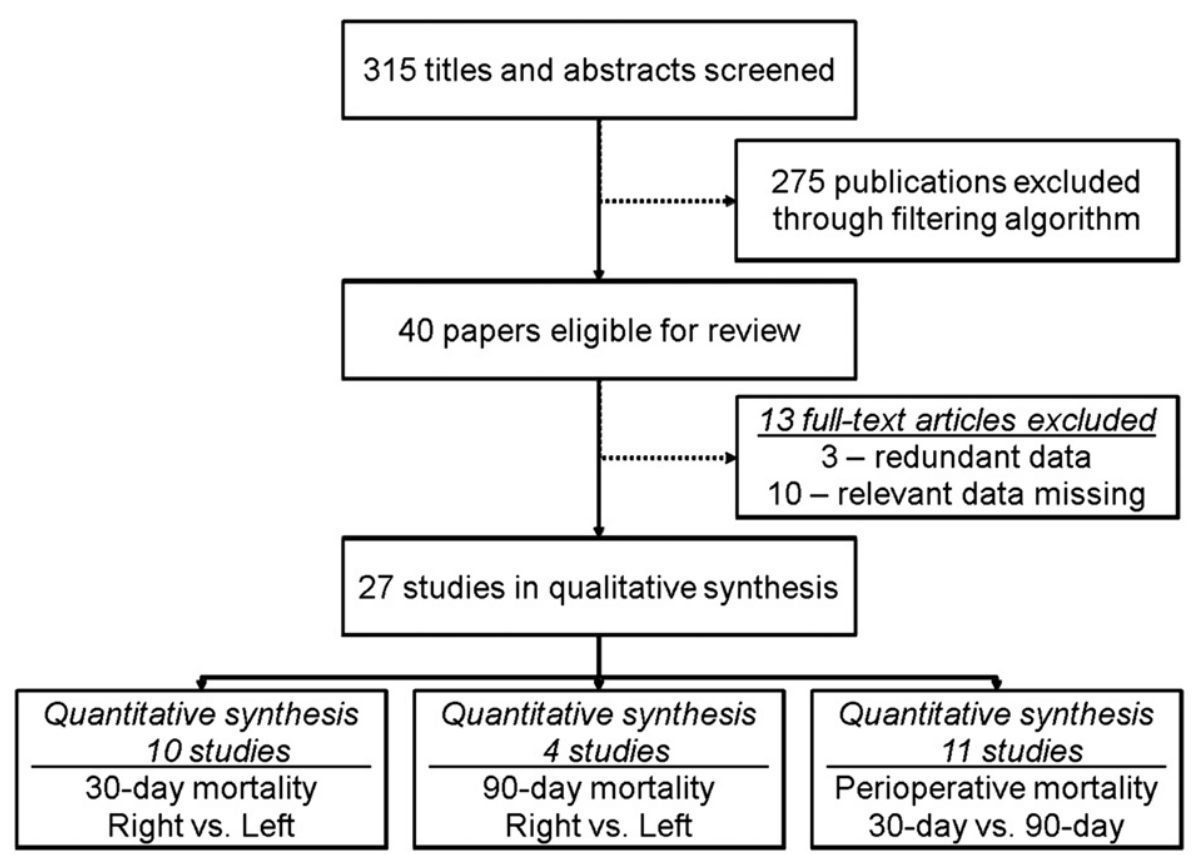

FIGURE 1. Publication search. Publications were initially identified with a PubMed search that used the terms "non-small cell lung cancer" with "pneumonectomy," "induction," and "neoadjuvant." The 315 publications identified were then filtered by a review of the titles, abstracts, and publications to yield 40 eligible publications. These 40 publications were reviewed fully for content, and ultimately 27 studies were included for qualitative analysis. Further refined numbers of studies were included for the various quantitative analyses.

\section{RESULTS}

\section{Results of Search}

The search strategy identified 315 articles (Figure 1). The individual articles were selected on the basis of year of publication but without regard to the dates of the operations described in the methods and results sections. After screening of the titles and, when appropriate, the abstracts or actual articles, 40 articles were selected for full review. Nine studies were excluded because neither 30-day nor 90-day pneumonectomy-specific mortality was reported. ${ }^{7-15}$ Of the remaining 31 articles, that matched the selection criteria, 3 additional studies were excluded because of their redundant nature. The patients in 1 study ${ }^{16}$ were also included in a later article involving a substantially greater number of pneumonectomies. Two other articles ${ }^{17,18}$ were excluded for redundancy because they reported previously published work and were not as comprehensive in the desired data as the original articles. ${ }^{19,20}$ One included study ${ }^{21}$ involved a few sleeve pneumonectomies that could not be separated from the data reported; however, this articles was still included in the analysis because of the relatively small number of sleeve pneumonectomies, ${ }^{8}$ which represented $10 \%$ of the pneumonectomies performed in that study. There was 1 articles that included only 90-day mortality. ${ }^{22}$

Ultimately, there were 27 articles that were used for the analysis (Table 1). Of these 27 articles, 7 were prospective studies,19,23-27 and 20 were retrospective studies. ${ }^{15,16,20-22,28-44}$ Of the 7 prospective trials, 4 were randomized controlled trials ${ }^{2,19,24,27}$ and 3 were cohort studies..$^{23,25,26}$ Of the 20 retrospective studies, 8 were cohort studies $39-40,42-45$ and 12 were descriptive studies. $16,18,20,28-30,32-34,36-38,41,46$

\section{Study Quality}

The 27 studies selected for this review were grouped into 3 subgroups: randomized controlled trials (prospective), cohort studies (prospective and retrospective), and descriptive studies (retrospective). Within these subgroups, the quality of each study was graded on the investigator-derived 6-point scoring system (Table 2). As would be expected, 3 of the 4 randomized controlled trials were of the highest quality. Among the cohort and descriptive studies, there were 1 of 11 and 2 of 12 studies that were of the highest quality, respectively. Study quality did not significantly affect either the 30-day mortality or the 90-day mortality.

\section{Publication Bias and Heterogeneity}

Funnel plots generated for each of the subgroups demonstrated that there was no significant publication bias among studies reporting increased 30-day and 90-day mortalities for right-sided relative to left-sided pneumonectomy or increased 90 -day mortality relative to 30 day mortality (Figure 2). There were 15 studies reporting side-specific 30-day mortality, with 5 being excluded from the 30-day funnel plots. There were 6 studies 
TABLE 1. Summary of characteristics of studies of pneumonectomy after neoadjuvant therapy

\begin{tabular}{|c|c|c|c|c|c|c|c|c|c|c|c|c|}
\hline \multirow[b]{2}{*}{ Study } & \multirow[b]{2}{*}{ Period } & \multirow{2}{*}{$\begin{array}{l}\text { No. of } \\
\text { sites }\end{array}$} & \multirow{2}{*}{$\begin{array}{c}\text { Invasively } \\
\text { staged }\end{array}$} & \multirow{2}{*}{$\begin{array}{c}\text { Clinical stage } \\
\text { III ( } \%)\end{array}$} & \multirow[b]{2}{*}{ RT } & \multirow{2}{*}{$\begin{array}{l}\text { Dose } \\
\text { (Gy) }\end{array}$} & \multicolumn{3}{|c|}{ Total patients (no.) } & \multicolumn{3}{|c|}{ 30-d mortality (no.) } \\
\hline & & & & & & & All & Right & Left & All & Right & Left \\
\hline \multicolumn{13}{|c|}{ Prospective randomized, controlled trials } \\
\hline Albain ${ }^{2}$ & 1994-2001 & Multiple & All & 100 & Yes & 45 & 54 & 29 & 25 & $14(26 \%)$ & $11(38 \%)$ & $3(10 \%)$ \\
\hline Van Schil ${ }^{17,19}$ & 1994-2002 & Multiple & All & 100 & No & - & $69^{*}$ & 35 & 33 & $5(7 \%)$ & $2(6 \%)$ & $3(9 \%)$ \\
\hline Thomas $^{27}$ & $1995-2003$ & Multiple & All & 100 & Some & $54 \mathrm{HF}$ & 104 & 39 & 65 & $10(10 \%)$ & - & - \\
\hline Gilligan $^{24}$ & 1997-2005 & Multiple & Some & 8 & No & - & 59 & - & - & $3(5 \%)$ & - & - \\
\hline \multicolumn{13}{|l|}{ Prospective cohort } \\
\hline Pezzetta $^{26}$ & 1994-2003 & Single & All & 100 & Yes & $44 \mathrm{HF}$ & 34 & 19 & 15 & 0 & 0 & 0 \\
\hline Lorent $^{25}$ & 1995-1998 & Single & All & 100 & No & - & 31 & - & - & 0 & - & - \\
\hline Garrido $^{23}$ & 1999-2003 & Multiple & All & 10 & No & - & 37 & 20 & 17 & $7(19 \%)$ & $6(30 \%)$ & $1(6 \%)$ \\
\hline \multicolumn{13}{|c|}{ Retrospective cohort } \\
\hline D'Amato ${ }^{31}$ & 1989-2004 & Dual & Unknown & Unknown & No & - & 68 & 37 & 31 & $14(21 \%)$ & - & - \\
\hline Gaissert $^{35}$ & 1993-2007 & Single & All & 93 & Yes & $42-72$ & 46 & 22 & 24 & $2(4 \%)$ & $1(4 \%)$ & $1(4 \%)$ \\
\hline Gudbjartsson $^{39}$ & $1996-2003$ & Single & All & 88 & Yes & 44 & 35 & 16 & 19 & 0 & 0 & 0 \\
\hline $\mathrm{Leo}^{44}$ & 1998-2005 & Single & Some & 53 & No & - & 99 & 52 & 47 & $3(3 \%)$ & - & - \\
\hline Mansour $^{40}$ & 1999-2007 & Single & Unknown & Unknown & No & - & 60 & 29 & 31 & $4(7 \%)$ & $2(7 \%)$ & $2(6 \%)$ \\
\hline $\operatorname{Refai}^{43}$ & $2000-2007$ & Single & Some & Unknown & Some & Unknown & $102 \dagger$ & - & - & $6(6 \%)$ & - & - \\
\hline Stefani $^{21}$ & 2001-2007 & Single & Some & 100 & No & - & $79 \ddagger$ & - & - & $6(8 \%)$ & - & - \\
\hline Brouchet $^{42}$ & 2002-2004 & Multiple & Unknown & Unknown & No & - & 195 & - & - & $8(4 \%)$ & - & - \\
\hline \multicolumn{13}{|l|}{ Descriptive } \\
\hline $\mathrm{Kim}^{32}$ & 1983-2007 & Single & Some & 95 & Yes & $40-45$ & 129 & 65 & 64 & $8(6 \%) \S$ & $6(9 \%)$ & $2(3 \%)$ \\
\hline Doddoli $^{16,46}$ & 1989-2003 & Single & Some & 98 & Some & $30-45$ & 100 & 55 & 45 & $12(12 \%)$ & $9(16 \%)$ & $3(7 \%)$ \\
\hline Daly $^{30}$ & 1990-2005 & Single & Some & 63 & Yes & 59 & 30 & 18 & 12 & $4(13 \%)$ & $1(6 \%)$ & $3(25 \%)$ \\
\hline Carretta $^{33}$ & $1991-2005$ & Single & Some & 100 & No & - & 30 & - & - & $1(3 \%)$ & - & - \\
\hline Stamatis ${ }^{34}$ & $1991-2002$ & Multiple & All & 100 & Yes & 45 & 133 & - & - & $9(7 \%)$ & - & - \\
\hline Venuta $^{28}$ & 1992-2006 & Single & All & 100 & Some & $40-50$ & 32 & 18 & 14 & $4(12 \%)$ & $3(17 \%)$ & $1(7 \%)$ \\
\hline Thibout $^{29}$ & 1993-2006 & Multiple & Some & 45 & No & - & 228 & 117 & 111 & $11(5 \%)$ & - & - \\
\hline $\operatorname{Martin}^{18,20}$ & 1993-1999 & Single & Some & 70 & Some & $10-72$ & 97 & 46 & 51 & $6(6 \%)$ & $6(13 \%)$ & 0 \\
\hline Perrot $^{36}$ & 1993-2002 & Single & Some & 79 & No & - & 55 & 27 & 28 & $1(2 \%)$ & $1(4 \%)$ & 0 \\
\hline Krasna $^{38}$ & 1995-2005 & Single & Unknown & 96 & Yes & 61 & 29 & 15 & 14 & 0 & 0 & 0 \\
\hline Allen $^{37}$ & 1995-2005 & Single & Unknown & 88 & Some & 54 & 73 & 28 & 45 & $4(6 \%)$ & - & - \\
\hline Alifano $^{41}$ & 2000-2006 & Single & Some & Unknown & No & - & 118 & 54 & 64 & $7(6 \%)$ & $4(7 \%)$ & $3(5 \%)$ \\
\hline
\end{tabular}

All the studies listed used platinum-based chemotherapy. $R T$, Radiation therapy; $H F$, hyperfractionated. *Unknown laterality in 1 case. $\dagger$ Total number from which analysis performed was 77 . $\ddagger$ Includes 10 tracheal pneumonectomies. $§$ Not published, but known to authors.

reporting side-specific 90-day mortality, with 2 being excluded from the 90-day mortality funnel plots. The studies were excluded because either the total mortality, the right-sided mortality, or the left-sided mortality was $0 \%$. In these studies, the individual odds ratio and variance for each study would both be infinity. In the metaanalysis, the weight associated with each study was 0 , and these studies therefore would not contribute to the final estimate of odds ratio. The test for heterogeneity demonstrated that there was no substantial heterogeneity among the groups and subgroups when evaluated in terms of 30-day and 90-day mortalities for right versus left pneumonectomy or increased 90-day mortality relative to 30-day mortality.

\section{Right Versus Left Pneumonectomy}

Perioperative mortality at 30 days. The overall 30-day mortality among the 27 studies was 7\% (Table 2). Among the 15 studies reporting side-specific 30-day mortality, the cumulative mortalities were $11 \%$ and $5 \%$ for right and left pneumonectomies, respectively (Figure 3). In the meta-analysis of 10 studies, the odds ratio of the 30-day mortality (right vs left pneumonectomy) was 1.97 (95\% confidence interval, 1.113.49). This effect was statistically significant $(P=.02)$. No significant heterogeneity results were found $\left(I^{2}=0.7 \%\right)$.

Perioperative mortality at 90 days. The overall 90 -day mortality among the 27 studies was $12 \%$. Among the 6 studies reporting side-specific 90-day mortality, the cumulative mortalities were $20 \%$ and $9 \%$ for right and left pneumonectomies, respectively (Figure 3). In the meta-analysis of 4 studies, the odds ratio for 90-day mortality for right pneumonectomy vs left pneumonectomy was $2.01 \quad(95 \%$ confidence interval, 1.09-3.72). This effect was statistically significant $(P=.03)$. No significant heterogeneity results was found $\left(I^{2}=0.7 \%\right)$. 
TABLE 2. Assessment of study quality

\begin{tabular}{|c|c|c|c|c|c|c|c|}
\hline Reference & $\begin{array}{c}\text { Long study } \\
\text { period }\end{array}$ & $\begin{array}{c}\text { Later } \\
\text { study era }\end{array}$ & $\begin{array}{c}\text { Large study } \\
\text { size }\end{array}$ & $\begin{array}{c}\text { Multiple } \\
\text { sites }\end{array}$ & $\begin{array}{c}\text { Used invasive } \\
\text { staging }\end{array}$ & $\begin{array}{c}>\mathbf{5 0} \% \text { clinical } \\
\text { stage III }\end{array}$ & $\begin{array}{l}\text { Cumulative } \\
\text { quality rank }\end{array}$ \\
\hline \multicolumn{8}{|c|}{ Prospective randomized controlled trials } \\
\hline Albain ${ }^{2}$ & No & Yes & No & Yes & Yes & Yes & Highest \\
\hline Van Schil ${ }^{17,19}$ & Yes & Yes & Yes & Yes & Yes & Yes & Highest \\
\hline Thomas $^{27}$ & Yes & Yes & Yes & Yes & Yes & Yes & Highest \\
\hline Gilligan $^{24}$ & Yes & Yes & No & Yes & No & No & High \\
\hline \multicolumn{8}{|l|}{ Prospective cohort } \\
\hline Pezzetta $^{26}$ & Yes & Yes & No & No & Yes & Yes & Highest \\
\hline Lorent $^{25}$ & No & Yes & No & No & Yes & Yes & High \\
\hline Garrido $^{23}$ & No & Yes & No & Yes & Yes & No & High \\
\hline \multicolumn{8}{|c|}{ Retrospective cohort } \\
\hline D'Amato $^{31}$ & Yes & No & Yes & Yes & No & No & High \\
\hline Gaissert $^{35}$ & Yes & No & No & No & Yes & Yes & High \\
\hline Gudbjartsson $^{39}$ & No & Yes & No & No & Yes & Yes & High \\
\hline $\mathrm{Leo}^{44}$ & No & Yes & Yes & No & No & Yes & High \\
\hline Mansour $^{40}$ & Yes & Yes & No & No & No & No & High \\
\hline Refai $^{43}$ & No & Yes & Yes & No & No & No & High \\
\hline Stefani $^{21}$ & No & Yes & Yes & No & No & Yes & High \\
\hline Brouchet $^{42}$ & No & Yes & Yes & Yes & No & No & High \\
\hline \multicolumn{8}{|l|}{ Descriptive } \\
\hline $\mathrm{Kim}^{32}$ & Yes & No & Yes & No & No & Yes & High \\
\hline Doddoli $^{16,46}$ & Yes & No & Yes & No & No & Yes & High \\
\hline Daly ${ }^{30}$ & Yes & No & No & No & No & Yes & High \\
\hline Carretta $^{33}$ & Yes & No & No & No & No & Yes & High \\
\hline Stamatis $^{34}$ & Yes & No & Yes & Yes & Yes & Yes & Highest \\
\hline Venuta $^{28}$ & Yes & No & No & No & Yes & Yes & High \\
\hline Thibout $^{29}$ & Yes & No & Yes & Yes & No & No & High \\
\hline $\operatorname{Martin}^{18,20}$ & No & No & Yes & No & No & Yes & High \\
\hline Perrot $^{36}$ & Yes & No & No & No & No & Yes & High \\
\hline Krasna $^{38}$ & Yes & Yes & No & No & No & Yes & High \\
\hline Allen ${ }^{37}$ & Yes & Yes & Yes & No & No & Yes & Highest \\
\hline Alifano $^{41}$ & No & Yes & Yes & No & No & No & High \\
\hline
\end{tabular}

The median number of years $(<8$ or $\geq 8)$ was used to determine whether the study was long or not long. Studies published after and including 1994 or before 1994 were considered later or earlier studies, respectively. The median number of patients included among all the studies $(<68$ or $\geq 68)$ was used to dichotomize studies as large or not large. The number of institutions involved were grouped into 1 versus more than 1 because of speculation that this difference would be more revealing than a threshold of a given number of multiple institutions (eg, $4 \mathrm{vs} \geq 5$ ). Performance of invasive mediastinal staging routinely in all the patients versus in some or an unknown number of patients was used to dichotomize the studies.

\section{Difference Between 30-Day and 90-Day Perioperative Mortalities}

Both 30-day and 90-day mortality data were reported in 11 studies; the other 16 provided only one set of data or the other. These 11 studies were thought to provide a more accurate comparison of 30 and 90-day mortalities (Table 3). From these 11 studies, the 90-day mortality was apparently significantly higher than the 30-day mortality (difference, $5 \%$; $95 \%$ confidence interval, $4.0 \%-6.8 \%$; $\left.P<.0001, I^{2}=0\right)$. Among these studies, increases from 30 day to 90 -day mortality were statistically significant on both the right side $(9 \% ; P=.0001)$ and the left side $(7 \%$; $P=.001)$.

\section{Effect of Radiation Therapy}

The use of radiation therapy was not associated with any increases in 30-day or 90-day mortality. A lack of any significant findings was observed when comparing studies that routinely used radiation with those that either used it sometimes or never described its use, as well as when the latter 2 groups were combined (routinely vs sometimes and never).

\section{Causes of Perioperative Mortality}

Information regarding cause of 30-day mortality after pneumonectomy after neoadjuvant therapy were provided in 11 studies (1 prospective ${ }^{2}$ and 10 retrospective $\left.\mathrm{e}^{16,30-32,34,35,37,41,44,47}\right)$. Half of the perioperative deaths were caused by a pulmonary complication (Figure 4), with the other categories divided approximately equally. There were only 7 studies that reported details of the causes of 90-day mortality. ${ }^{16,22,26,29,32,37,38}$ Pulmonary complications still accounted for the most 


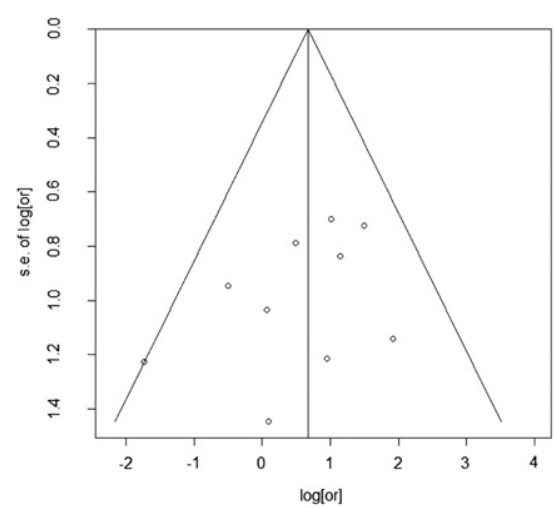

A

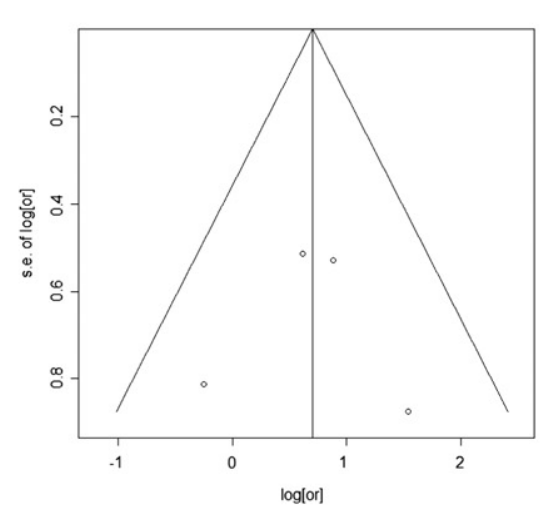

B Egger's Test $p=0.969$

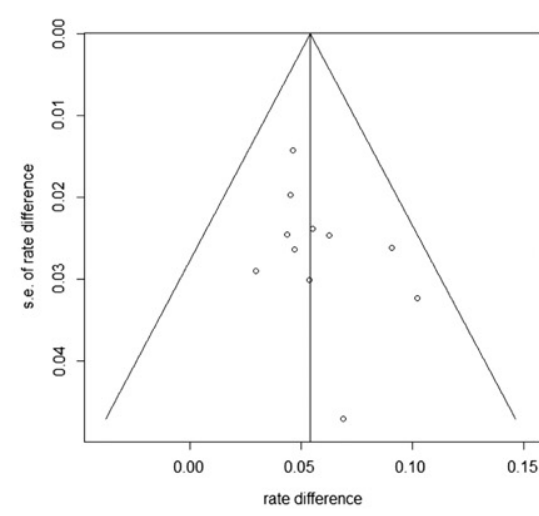

C Egger's Test $\mathrm{p}=0.198$

FIGURE 2. Assessment of publication bias. With Begg funnel plots and Egger tests, a quantitative assessment of publication bias was performed for 30-day mortality between right-sided and left-sided pneumonectomies (A), 90-day mortality between right-sided and left-sided pneumonectomies (B), and 30-day mortality versus 90-day mortality (C).

deaths $(40 \%)$, but there were also more in the "other" category. In addition, there were more infections complications as a cause of 90-day mortality than of 30day mortality ( $24 \%$ vs $14 \% ; P=.012)$.

\section{DISCUSSION}

\section{Impact of Laterality of Resection}

A specific focus of this review was exploring the answer to the question of whether a right pneumonectomy after neoadjuvant therapy justified or to be avoided. The Intergroup 0139 trial $^{2}$ promoted concern about right pneumonectomy, because an (unplanned) subgroup analysis suggested that the observed 38\% 30-day mortality more than offset any benefit that might have resulted from adding surgery to the therapeutic strategy. The results of this metaanalysis suggest that right pneumonectomy is, in fact, associated with an increased risk of perioperative mortality. This study was not one in which the risk factors for perioperative

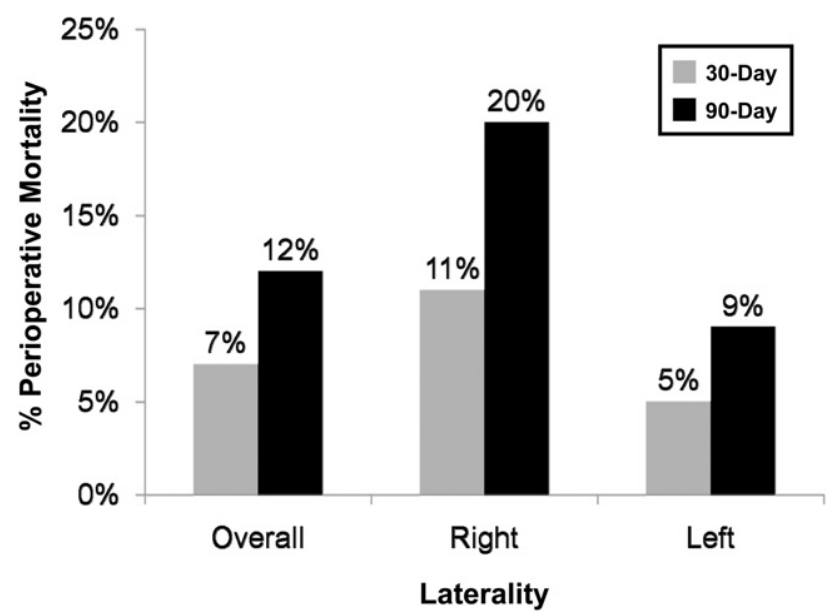

FIGURE 3. Perioperative mortality. Perioperative mortality represented according to overall, right, and left pneumonectomies for all 27 studies. death associated with neoadjuvant therapy and pneumonectomy were examined, however, and it is therefore impossible to know the actual reason for this increased risk.

It appears that a left pneumonectomy after neoadjuvant therapy can be justified from the standpoint of either 30- or 90-day mortality. Of course, the patients must be assessed for suitability for surgery, and it remains controversial whether surgery should be included in the treatment strategy for patients with $\mathrm{N} 2$ node involvement.

On the other hand, whether a right pneumonectomy is wise is less clear. It appears to be well justified on the basis of the 30-day mortality, and also of the experience of some institutions. The 90-day mortality is probably a better outcome measure, however, and the overall $20 \%$ average mortality raises concern. Perhaps the conclusion should be that patients should be selected very carefully for this approach and that it should be done primarily in centers with sufficient experience and with a documented low mortality for right pneumonectomy after neoadjuvant therapy. The data clearly demonstrate a strong correlation between pneumonectomy mortality and center volume, as well as surgeon specialization and a focus on noncardiac thoracic surgery. ${ }^{48,49}$

Several additional articles are important, although they were excluded from this review because they did not meet criteria to be included in the analysis. These studies independently found that a right pneumonectomy after neoadjuvant therapy carried a higher incidence of complications that may have contributed to a higher perioperative mortality. ${ }^{15,20,50}$

\section{Difference in 30-Day and 90-Day Mortalities}

What is the best measure of perioperative mortality? Traditionally, 30-day or in-hospital mortality has been chosen. Most studies now, however, report only 30-day mortality. It is easier to identify the dates of surgery and of death 
TABLE 3. Summary of 90-day mortality associated with pneumonectomy after neoadjuvant therapy from the studies that provided both 30-day and 90-day mortalities

\begin{tabular}{|c|c|c|c|}
\hline \multirow[b]{2}{*}{ Authors } & \multicolumn{3}{|c|}{ Total 90-d mortality (no.) } \\
\hline & All & Right & Left \\
\hline \multicolumn{4}{|c|}{ Prospective randomized controlled trials } \\
\hline Van Schil ${ }^{17,19}$ & $8 / 69(11 \%)$ & - & - \\
\hline \multicolumn{4}{|l|}{ Prospective cohort } \\
\hline Pezzetta $^{26}$ & $1 / 34(3 \%)$ & - & - \\
\hline \multicolumn{4}{|c|}{ Retrospective cohort } \\
\hline Mansour ${ }^{40}$ & $7 / 60(12 \%)$ & $3 / 29(10 \%)$ & $4 / 31(13 \%)$ \\
\hline $\operatorname{Refai}^{43} \dagger$ & $12 / 102(12 \%)$ & - & - \\
\hline \multicolumn{4}{|l|}{ Descriptive } \\
\hline $\mathrm{Kim}^{32}$ & $19 / 129(15 \%)$ & $13 / 65(20 \%)$ & $6 / 64(9 \%)$ \\
\hline Doddoli $^{16,46}$ & $21 / 100(21 \%)$ & $14 / 55(25 \%)$ & $7 / 45(15 \%)$ \\
\hline Thibout $^{29}$ & $21 / 228(9 \%)$ & - & - \\
\hline $\operatorname{Martin}^{18,20}$ & 11/97 (11\%) & $11 / 46(24 \%)$ & $0 / 51(0 \%)$ \\
\hline Krasna $^{38}$ & $2 / 29(7 \%)$ & $2 / 15(13 \%)$ & $0 / 14(0 \%)$ \\
\hline Allen $^{37}$ & $7 / 73(10 \%)$ & $5 / 28(18 \%)$ & $2 / 45(4 \%)$ \\
\hline Alifano $^{41}$ & $13 / 118(11 \%)$ & - & - \\
\hline Average & $122 / 1039(12 \%)$ & $48 / 238(20 \%)$ & $22 / 250(9 \%)$ \\
\hline
\end{tabular}

than to verify that the patient was continually hospitalized. It may also be true that at one time most deaths related to a surgical procedure occurred within 30 days. With better intensive care unit care and methods of life support, however, this may be changing. We found that 90 -day mortality appears to be a better measure to use, because it more accurately captures the impact of the surgical procedure. This is particularly true for right pneumonectomy, because the increase between 30 and 90 days was not so large for the left side.

We found that the reported 30-day mortality for a pneumonectomy after neoadjuvant therapy was similar to that reported for pneumonectomy in general. ${ }^{1,51}$ This is corroborated by other studies that have compared mortality of pneumonectomy with or without neoadjuvant therapy, which have also found no difference. ${ }^{15,35,39,40,42-44,52}$ Much sparser data are available for 90-day mortality, and it is therefore difficult to make a comparison for 90-day mortality with and without neoadjuvant therapy.

The mortality at 90 days is significantly higher than at 30 days in our review. Doddoli and colleagues ${ }^{16}$ suggested that the 90-day mortality was a more accurate reflection of the mortality associated with pneumonectomy after neoadjuvant therapy. Although the 90-day mortality can naturally be expected to be higher than the 30-day mortality, it is rather surprising that the rate increased as substantially as it did, especially for right pneumonectomy. It is not clear whether the increase is because of neoadjuvant therapy, because of changes in cardiopulmonary function after pneumonectomy, or because it takes longer for complications to lead to actual death. ${ }^{53-55}$

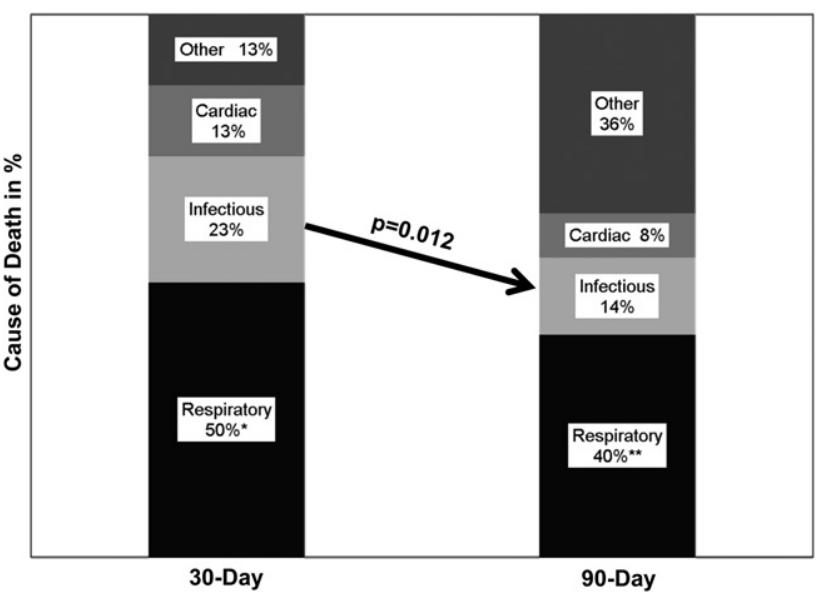

FIGURE 4. Cause of mortality. Infectious causes of death were significantly greater within a 30-day time frame than within a 90-day time frame $(P=.012)$. No other statistically significant differences in the distribution of complications for the 30-day period versus the 90-day period were observed. Significant differences in causes of death were also observed within the 90-day and 30-day periods. Asterisk indicates that the incidence of respiratory complications contributing to 30 -day mortality was significantly greater than those of the infectious, cardiac, or other causes $(P<.001)$. Double asterisk indicates that the incidence of respiratory or other complications contributing to 90 -day mortality was significantly greater than those of infectious or cardiac causes $(P<.001)$.

\section{Morbidities and Their Sequelae}

Pulmonary complications were the most common cause of death among patients undergoing neoadjuvant therapy and pneumonectomy. It is surprising that infectious complications were not a more common cause of death, in light of the frequent concern of bronchopleural fistula as a cause of death after pneumonectomy.

\section{Limitations}

A limitation of this review is that multiple investigators did not search and select the studies. Nevertheless, throughout the review process, exhaustive ancillary searches were performed to ensure that no studies were erroneously excluded. Another limitation of this review is that the chemotherapy regimens used among the different studies incorporated in this analysis were fairly diverse. These consistently involved platinum-based therapy, but there was variability in the second or third agent. This may have accounted for the higher incidence of complications in some studies, but this was not able to be analyzed. Additionally, the use of adjuvant therapies was not consistently reported, thus making it difficult to assess the impact of this factor. Another limitation is that no distinction could be made between a simple and a complex pneumonectomy. The increased complexity associated with an intrapericardial pneumonectomy could have contributed to some of the morbidity and 
quite possibly to the perioperative mortality that was observed.

\section{CONCLUSIONS}

Several conclusions can be drawn from our analysis. When the perioperative period is extended to 90 days, however, the mortality appears to increase substantially (nearly 2-fold). In the setting of obtaining informed consent, an explanation of the elevated risk associated with right pneumonectomy should be discussed. Pulmonary complications appear to contribute the most to perioperative mortality. The incidence of infectious complications appears to have a greater impact on 30-day mortality than on 90-day mortality. Regarding whether a pneumonectomy should be undertaken as part of the treatment strategy after neoadjuvant therapy, the answer appears to be, "It depends." It appears that in general this approach is justified for a left pneumonectomy; however, the mortality is high enough for a right pneumonectomy that resection must be considered carefully.

\section{References}

1. Allen MS, Darling GE, Pechet TT, Mitchell JD, Herndon JE 2nd, Landreneau RJ, et al. Morbidity and mortality of major pulmonary resections in patients with early-stage lung cancer: initial results of the randomized, prospective ACOSOG Z0030 trial. Ann Thorac Surg. 2006;81:1013-20.

2. Albain KS, Swann RS, Rusch VW, Turrisi AT 3rd, Shepherd FA, Smith C, et al. Radiotherapy plus chemotherapy with or without surgical resection for stage III non-small-cell lung cancer: a phase III randomised controlled trial. Lancet. 2009; 374:379-86.

3. Emerson JD, Burdick E, Hoaglin DC, Mosteller F, Chalmers TC. An empirical study of the possible relation of treatment differences to quality scores in controlled randomized clinical trials. Control Clin Trials. 1990;11:339-52.

4. Greenland S. Invited commentary: a critical look at some popular meta-analytic methods. American J Epidemiol. 1994;140:290-6.

5. Stroup DF, Berlin JA, Morton SC, Olkin I, Williamson GD, Rennie D, et al. Meta-analysis of observational studies in epidemiology: a proposal for reporting. Meta-analysis Of Observational Studies in Epidemiology (MOOSE) group. JAMA. 2000;283:2008-12.

6. Ihaka R, Gentlemen R. R: a language for data analysis and graphics. J Comput Graph Stat. 1996;5:299-314.

7. Girard N, Mornex F, Douillard JY, Bossard N, Quoix E, Beckendorf V, et al. Is neoadjuvant chemoradiotherapy a feasible strategy for stage IIIA-N2 non-small cell lung cancer? Mature results of the randomized IFCT-0101 phase II trial. Lung Cancer. 2010;69:86-93.

8. Gottfried M, Ramlau R, Krzakowski M, Ziolo G, Olechnowicz H, Koubkova L, et al. Cisplatin-based three drugs combination (NIP) as induction and adjuvant treatment in locally advanced non-small cell lung cancer: final results. $J$ Thorac Oncol. 2008;3:152-7.

9. Fujita S, Katakami N, Takahashi Y, Hirokawa K, Ikeda A, Tabata C, et al. Postoperative complications after induction chemoradiotherapy in patients with nonsmall-cell lung cancer. Eur J Cardiothorac Surg. 2006;29:896-901.

10. Friedel G, Hruska D, Budach W, Wolf M, Kyriss T, Hürtgen M, et al. Neoadjuvant chemoradiotherapy of stage III non-small-cell lung cancer. Lung Cancer. 2000;30:175-85.

11. Betticher DC, Hsu Schmitz SF, Tötsch M, Hansen E, Joss C, von Briel C, et al. Mediastinal lymph node clearance after docetaxel-cisplatin neoadjuvant chemotherapy is prognostic of survival in patients with stage IIIA pN2 non-small-cell lung cancer: a multicenter phase II trial. J Clin Oncol. 2003;21:1752-9.

12. Depierre A, Milleron B, Moro-Sibilot D, Chevret S, Quoix E, Lebeau B, et al Preoperative chemotherapy followed by surgery compared with primary surgery in resectable stage I (except T1N0), II, and IIIa non-small-cell lung cancer. J Clin Oncol. 2002;20:247-53.
13. DeCamp MM, Rice TW, Adelstein DJ, Chidel MA, Rybicki LA, Murthy SC, et al. Value of accelerated multimodality therapy in stage IIIA and IIIB nonsmall cell lung cancer. J Thorac Cardiovasc Surg. 2003;126:17-27.

14. Leo F, Scanagatta P, Baglio P, Radice D, Veronesi G, Solli P, et al. The risk of pneumonectomy over the age of 70. A case-control study. Eur J Cardiothorac Surg. 2007;31:780-2.

15. Evans NR 3rd, Li S, Wright CD, Allen MS, Gaissert HA. The impact of induction therapy on morbidity and operative mortality after resection of primary lung cancer. J Thorac Cardiovasc Surg. 2010;139:991-6,e1-2.

16. Doddoli C, Barlesi F, Trousse D, Robitail S, Yena S, Astoul P, et al. One hundred consecutive pneumonectomies after induction therapy for non-small cell lung cancer: an uncertain balance between risks and benefits. $J$ Thorac Cardiovasc Surg. 2005;130:416-25.

17. van Meerbeeck JP, Kramer GW, Van Schil PE, Legrand C, Smit EF, Schramel F, et al. Randomized controlled trial of resection versus radiotherapy after induction chemotherapy in stage IIIA-N2 non-small-cell lung cancer. J Natl Cancer Inst. 2007;99:442-50.

18. Martin J, Ginsberg RJ, Venkatraman ES, Bains MS, Downey RJ, Korst RJ, et al. Long-term results of combined-modality therapy in resectable non-small-cell lung cancer. J Clin Oncol. 2002;20:1989-95.

19. Van Schil P, Van Meerbeeck J, Kramer G, Splinter T, Legrand C, Giaccone G, et al. Morbidity and mortality in the surgery arm of EORTC 08941 trial. Eur Respir J. 2005;26:192-7.

20. Martin J, Ginsberg RJ, Abolhoda A, Bains MS, Downey RJ, Korst RJ, et al. Morbidity and mortality after neoadjuvant therapy for lung cancer: the risks of right pneumonectomy. Ann Thorac Surg. 2001;72:1149-54.

21. Stefani A, Alifano M, Bobbio A, Grigoroiu M, Jouni R, Magdeleinat P, et al. Which patients should be operated on after induction chemotherapy for N2 non-small cell lung cancer? Analysis of a 7-year experience in 175 patients. J Thorac Cardiovasc Surg. 2010;140:356-63.

22. Weder W, Collaud S, Eberhardt WE, Hillinger S, Welter S, Stahel R, et al. Pneumonectomy is a valuable treatment option after neoadjuvant therapy for stage III non-small cell lung cancer. J Thorac Cardiovasc Surg. 2010;139:1424-30.

23. Garrido P, González-Larriba JL, Insa A, Provencio M, Torres A, Isla D, et al. Long-term survival associated with complete resection after induction chemotherapy in stage IIIA (N2) and IIIB (T4N0-1) non small-cell lung cancer patients: the Spanish Lung Cancer Group Trial 9901. J Clin Oncol. 2007;25:4736-42.

24. Gilligan D, Nicolson M, Smith I, Groen H, Dalesio O, Goldstraw P, et al. Preoperative chemotherapy in patients with resectable non-small cell lung cancer: results of the MRC LU22/NVALT 2/EORTC 08012 multicentre randomised trial and update of systematic review. Lancet. 2007;369:1929-37.

25. Lorent N, De Leyn P, Lievens Y, Verbeken E, Nackaerts K, Dooms C, et al. Longterm survival of surgically staged IIIA-N2 non-small-cell lung cancer treated with surgical combined modality approach: analysis of a 7-year prospective experience. Ann Oncol. 2004;15:1645-53.

26. Pezzetta E, Stupp R, Zouhair A, Guillou L, Taffé P, von Briel C, et al. Comparison of neoadjuvant cisplatin-based chemotherapy versus radiochemotherapy followed by resection for stage III (N2) NSCLC. Eur J Cardiothorac Surg. 2005; 27:1092-8.

27. Thomas M, Rübe C, Hoffknecht P, Macha HN, Freitag L, Linder A, et al. Effect of preoperative chemoradiation in addition to preoperative chemotherapy: a randomised trial in stage III non-small-cell lung cancer. Lancet Oncol. 2008;9:636-48.

28. Venuta F, Anile M, Diso D, Ibrahim M, De Giacomo T, Rolla M, et al. Operative complications and early mortality after induction therapy for lung cancer. Eur $J$ Cardiothorac Surg. 2007;31:714-7.

29. Thibout Y, Guibert B, Bossard N, Tronc F, Tiffet O, de la Roche E, et al. Is pneumonectomy after induction chemotherapy for non-small cell lung cancer a reasonable procedure? A multicenter retrospective study of 228 cases. J Thorac Oncol. 2009; 4:1496-503.

30. Daly BD, Fernando HC, Ketchedjian A, Dipetrillo TA, Kachnic LA, Morelli DM, et al. Pneumonectomy after high-dose radiation and concurrent chemotherapy for nonsmall cell lung cancer. Ann Thorac Surg. 2006;82:227-31.

31. d'Amato TA, Ashrafi AS, Schuchert MJ, Alshehab DS, Seely AJ, Shamji FM, et al. Risk of pneumonectomy after induction therapy for locally advanced non-small cell lung cancer. Ann Thorac Surg. 2009;88:1079-85.

32. Kim AW, Faber LP, Warren WH, Basu S, Wightman SC, Weber JA, et al. Pneumonectomy after chemoradiation therapy for non-small cell lung cancer: does "side" really matter? Ann Thorac Surg. 2009;88:937-44.

33. Carretta A, Ciriaco P, Melloni G, Sayed I, Bandiera A, Ferla L, et al. Results of surgical treatment after neoadjuvant chemotherapy for stage III non-small cell lung cancer. World J Surg. 2008;32:2636-42. 
34. Stamatis G, Eberhard W, Pöttgen C. Surgery after multimodality treatment for non-small-cell lung cancer. Lung Cancer. 2004;45(Suppl. 2):S107-12.

35. Gaissert HA, Keum DY, Wright CD, Ancukiewicz M, Monroe E, Donahue DM, et al. POINT: Operative risk of pneumonectomy-influence of preoperative induction therapy. J Thorac Cardiovasc Surg. 2009;138:289-94.

36. Perrot E, Guibert B, Mulsant P, Blandin S, Arnaud I, Roy P, et al. Preoperative chemotherapy does not increase complications after nonsmall cell lung cancer resection. Ann Thorac Surg. 2005;80:423-7.

37. Allen A, Mentzer S, Yeap BY, Soto R, Baldini EH, Rabin MS, et al. Pneumonectomy after chemoradiation: the Dana-Farber Cancer Institute/Brigham and Women's Hospital experience. Cancer. 2008;112:1106-13.

38. Krasna MJ, Gamliel Z, Burrows WM, Sonett JR, Kwong KF, Edelman MJ, et al. Pneumonectomy for lung cancer after preoperative concurrent chemotherapy and high-dose radiation. Ann Thorac Surg. 2010;89:200-6.

39. Gudbjartsson T, Gyllstedt E, Pikwer A, Jönsson P. Early surgical results after pneumonectomy for non-small cell lung cancer are not affected by preoperative radiotherapy and chemotherapy. Ann Thorac Surg. 2008;86:376-82.

40. Mansour Z, Kochetkova EA, Ducrocq X, Vasilescu MD, Maxant G, Buggenhout $\mathrm{A}$, et al. Induction chemotherapy does not increase the operative risk of pneumonectomy! Eur J Cardiothorac Surg. 2007;31:181-5.

41. Alifano M, Boudaya MS, Salvi M, Collet JY, Dinu C, Camilleri-Broët S, et al. Pneumonectomy after chemotherapy: morbidity, mortality, and long-term outcome. Ann Thorac Surg. 2008;85:1866-73.

42. Brouchet LM, Bauvin EM, Marcheix BM, Bigay-Game L, Renaud C, Berjaud J, et al. Impact of induction treatment on postoperative complications in the treatment of non-small cell lung cancer. $J$ Thorac Oncol. 2007;2:626-31.

43. Refai M, Brunelli A, Rocco G, Ferguson MK, Fortiparri SN, Salati M, et al. Does induction treatment increase the risk of morbidity and mortality after pneumonectomy? A multicentre case-matched analysis. Eur J Cardiothorac Surg. 2010;37:535-9.

44. Leo F, Solli P, Veronesi G, Radice D, Floridi A, Gasparri R, et al. Does chemotherapy increase the risk of respiratory complications after pneumonectomy? J Thorac Cardiovasc Surg. 2006;132:519-23.
45. d'Amato T, Pettiford B, Schuchert M, Parker R, Ricketts WA, Luketich JD, et al Survival among patients with platinum resistant, locally advanced non-small cell lung cancer treated with platinum-based systemic therapy. Ann Surg Oncol. 2009;16:2848-55.

46. Doddoli C, Thomas P, Thirion X, Serée Y, Giudicelli R, Fuentes P. Postoperative complications in relation with induction therapy for lung cancer. Eur J Cardiothorac Surg. 2001;20:385-90.

47. Venuta F, Ciccone AM, Anile M, Ibrahim M, De Giacomo T, Coloni GF, et al Reconstruction of the pulmonary artery for lung cancer: long-term results. J Thorac Cardiovasc Surg. 2009;138:1185-91.

48. Birkmeyer JD, Siewers AE, Finlayson EV, Stukel TA, Lucas FL, Batista I, et al Hospital volume and surgical mortality in the United States. N Engl J Med. 2002 346:1128-37.

49. Goodney P, Lucas F, Stukel T, Birkmeyer J. Surgeon specialty and operative mortality with lung resection. Ann Surg. 2005;241:179-84.

50. Bernard A, Deschamps C, Allen MS, Miller DL, Trastek VF, Jenkins GD, et al Pneumonectomy for malignant disease: factors affecting early morbidity and mortality. J Thorac Cardiovasc Surg. 2001;121:1076-82.

51. Boffa DJ, Allen MS, Grab JD, Gaissert HA, Harpole DH, Wright CD. Data from The Society of Thoracic Surgeons general thoracic surgery database: the surgical management of primary lung tumors. J Thorac Cardiovasc Surg. 2008;135:247-54

52. Mansour Z, Kochetkova E, Santelmo N, Meyer P, Wihlm JM, Quoix E, et al. Risk factors for early mortality and morbidity after pneumonectomy: a reappraisal. Ann Thorac Surg. 2009;88:1737-44.

53. Cerfolio RJ, Talati A, Bryant AS. Changes in pulmonary function tests after neoadjuvant therapy predict postoperative complications. Ann Thorac Surg. 2009 88:930-6.

54. Leo F, Solli P, Spaggiari L, Veronesi G, de Braud F, Leon ME, et al. Respiratory function changes after chemotherapy: an additional risk for postoperative respiratory complications? Ann Thorac Surg. 2004;77:260-5.

55. Takeda S, Funakoshi Y, Kadota Y, Koma M, Maeda H, Kawamura S, et al. Fall in diffusing capacity associated with induction therapy for lung cancer: a predictor of postoperative complication? Ann Thorac Surg. 2006;82:232-6. 